\title{
Leaders
}

\section{Guidelines for the initial biopsy diagnosis of suspected chronic idiopathic inflammatory bowel disease. The British Society of Gastroenterology Initiative}

D Jenkins, M Balsitis, S Gallivan, M F Dixon, H M Gilmour, N A Shepherd, A Theodossi, G T Williams

Division of

Histopathology,

University Hospital,

Queen's Medical

Centre, Nottingham

D Jenkins

M Balsitis

Clinical Operational

Research Unit,

Department of

Statistical Science,

University College

London

S Gallivan

Department of

Pathology, Leeds

General Infirmary,

Leeds

M F Dixon

Department of Pathology, University of Edinburgh,

Edinburgh

H M Gilmour

Department of Pathology,

Gloucestershire Royal

Hospital, Gloucester

N A Shepherd

\section{Department of}

Gastroenterology,

Mayday Hospital,

London

A Theodossi

Department of Pathology, University of Wales College of Medicine, Cardiff $\mathrm{G} T$ Williams

Correspondence to: Dr D Jenkins, Division of Histopathology, Department of Clinical Laboratory Sciences, University Hospital, Queens Medical Centre, Nottingham NG7 2UH

Accepted for publication 12 August 1996

\section{Introduction}

Unambiguous interpretation of colorectal biopsy specimens is important for clinical decisions in the investigation of suspected chronic idiopathic inflammatory bowel disease (IBD). Variability of reporting style and terms such as mild inflammatory change and nonspecific proctitis/colitis may hide pathologists' difficulties with diagnostic uncertainty and confuse clinical management. Four main problems underlie these difficulties:

(1) lack of awareness of the range of normal colorectal histology and the minimal features which indicate clinically important inflammation;

(2) wide overlap in the pathological changes of most large bowel inflammatory diseases;

(3) lack of awareness of the accuracy and reproducibility of many changes used in diagnosis; and

(4) absence of standard terminology for pathological description and diagnosis.

On behalf of the British Society of Gastroenterology, we have used an evidence-based approach to compile guidelines for the biopsy diagnosis of suspected chronic idiopathic IBD ${ }^{\dagger}$. The guidelines are aimed primarily at improved accuracy of diagnosis when colorectal biopsy is used in the initial investigation of patients with diarrhoea. The objectives are to assist: the recognition of normal colorectal mucosa; the detection of important minor inflammatory change needing further investigation; the early diagnosis of chronic idiopathic IBD; the distinction between ulcerative colitis and Crohn's disease; the recognition of infective type colitis; and the diagnosis of less frequent forms of colitis. The guidelines include recommendations for minimum clinical information, useful morphological features, standardised terminology, and a clinically relevant reporting format. The evidence is from Europe and North America, and the conclusions should not be applied uncritically where the prevalence and the nature of the diseases are very different.

\section{Method for development of \\ evidence-based guidelines}

The development of the guidelines was based on systematic literature review presented to an expert consensus panel composed of gastrointestinal pathologists, an operational researcher and a gastrointestinal physician interested in diagnostic decision making. Original research into the reproducibility, sensitivity and specificity of individual microscopic features for the histological diagnosis of colorectal mucosal inflammation, together with studies reporting equivalent measured changes in colorectal mucosa, was sought, using Medline and Bath Information Data Services (BIDS) and consultation with experts. ${ }^{1-7}$ For subjective histopathological studies, only those microscopic findings which achieved moderate reproducibility, as judged by a minimum kappa value of 0.4 or a percentage agreement of at least $80 \%$, were selected. Features which did not achieve a diagnostic sensitivity or specificity of $50 \%$ in at least one study were excluded. When there was complete disagreement between studies, a feature was judged of uncertain value and excluded.

The quality of all the evidence considered by the panel was divided into three grades on the basis of the recommendations of the EvidenceBased Medicine Working Party for diagnostic studies. ${ }^{8}$ This is indicated by stars in the text: $\star \star \star$ evidence from more than one valid study of adequate size in a relevant clinical setting that a histopathological feature used in diagnosis was accurate and objective or reproducible; ${ }^{\star \star}$ evidence of diagnostic value from a single valid

†The British Society of Gastroenterology will be publishing Guidelines for the initial biopsy diagnosis of chronic idiopathic IBD $-A$ structured approach to biopsy assessment, which includes a more detailed description of biopsy assessment, based on the approach described in this paper. 
Table 1 Frequency of detection of the reproducible features for each diagnosis

\begin{tabular}{|c|c|c|c|c|c|c|}
\hline \multirow[b]{2}{*}{ Feature } & \multicolumn{5}{|c|}{ Frequency of detection (\%) } & \multirow[b]{2}{*}{ Study } \\
\hline & Normal & Infective & Chronic idiopathic IBD & Ulcerative colitis & Crohn's disease & \\
\hline \multicolumn{7}{|l|}{ Architecture } \\
\hline Surface irregularity & $0-5$ & $0-7$ & & 63 & 24 & 4,5 \\
\hline Villous surface & $0-6$ & & 39 & 30 & 12 & 2,7 \\
\hline Villous surface (v:cr >1.5:1) & 0 & & & 17 & 0 & 4 \\
\hline Crypt numbers $(<6 / \mathrm{mm})$ & 10 & 0 & 95 & & & 5 \\
\hline Branched crypts & $0-5$ & & 75 & $63-83$ & $39-67$ & 4,7 \\
\hline Crypt atrophy (shortening) & $0-5$ & 0 & & $29-78$ & $12-37$ & $1,2,7$ \\
\hline Abnormal crypt architecture & $0-11$ & $0-30$ & $49-66$ & $57-100$ & $27-71$ & $1,2,3,6,7$ \\
\hline \multicolumn{7}{|l|}{ Chronic inflammation } \\
\hline Increased LP cellularity & $0-19$ & 30 & $89-93$ & $76-92$ & $72-81$ & $3,4,6$ \\
\hline Superficial:basal $(<1.16: 1)^{\star}$ & 0 & 5 & 95 & & & 5 \\
\hline Increased basal cellularity & 0 & 0 & & 63 & 62 & 4,5 \\
\hline Basal lymphoid aggregates & & 0 & & 21 & 12 & 2 \\
\hline Basal giant cells & & $0-2$ & $13-16$ & 11 & 12 & 2,3 \\
\hline Granulomas & 0 & $0-2$ & $25-27$ & $0-5$ & $21-100$ & $1-4,6,7$ \\
\hline Discontinuous inflammation & 7 & & & 10 & 26 & 7 \\
\hline \multicolumn{7}{|l|}{ Acute inflammation } \\
\hline Crypt intraepithelial polymorphs & 0 & & 80 & $64-86$ & $48-75$ & 4,6 \\
\hline $1-10 \mathrm{NP} / \mathrm{crypt}$ & 4 & 39 & 47 & & & 5 \\
\hline$>10 \mathrm{NP} / \mathrm{crypt}$ & 0 & 0 & 18 & & & 5 \\
\hline Crypt abscesses & & & & 41 & 19 & 6 \\
\hline Abscesses-distensive & 1 & & & 18 & 32 & 7 \\
\hline Abscesses-disruptive & 0 & & & 14 & 26 & 7 \\
\hline Crypt neutrophilia & $0-2$ & & & $53-86$ & $56-75$ & 4,7 \\
\hline 1-10 NP/crypt lumen & 0 & 17 & 17 & & & 5 \\
\hline$>10 \mathrm{NP} /$ crypt lumen & 0 & 0 & 7 & & & 5 \\
\hline LP polymorphs increased & 6 & 14 & 59 & $61-63$ & $55-61$ & $2,6,7$ \\
\hline $10-100 \mathrm{NP} / \mathrm{mm} \mathrm{LP}$ & 43 & 72 & 45 & & & 5 \\
\hline $100-1000 \mathrm{NP} / \mathrm{mm} \mathrm{LP}$ & 0 & 17 & 48 & & & 5 \\
\hline$>1000 \mathrm{NP} / \mathrm{mm} \mathrm{LP}$ & 0 & 0 & 6 & & & 5 \\
\hline \multicolumn{7}{|l|}{ Epithelium } \\
\hline Surface erosions & & $0-9$ & $24-29$ & 37 & 8 & 2 \\
\hline Mucin depletion & 17 & & & $35-69$ & $5-57$ & $1,6,7$ \\
\hline
\end{tabular}

$\mathrm{v}: \mathrm{cr}=$ ratio of villus height to crypt layer thickness; $\mathrm{LP}=$ lamina propria; $\mathrm{NP}=$ neutrophil polymorphs.

*Superficial:basal=ratio of cellularity of superficial lamina propria to basal lamina propria.

quantitative paper, a single paper measuring accuracy or reproducibility, or from an appropriate descriptive case series in which adequate numbers of cases were clearly described in a relevant clinical setting; ${ }^{\star}$ opinion expressed in reviews, textbooks and by experts with no other formal validation available, no published measurement of accuracy or reproducibility available or adequate, appropriate case series.

The frequency of detection of the important reproducible features in the different diagnostic categories was compared (table 1).

Definitions of histological abnormalities The histological features useful for diagnosis of colorectal biopsy specimens were identified from the literature and grouped into four main categories: mucosal architecture, lamina propria cellularity, neutrophil polymorph infiltration, and epithelial abnormality. The results of the systematic review are summarised in table 1 . Awareness of the normal range of appearances of colorectal mucosa is necessary for optimum interpretation of biopsy specimens. ${ }^{5-11}$

\section{MUCOSAL ARCHITECTURE}

Mucosal architectural abnormality is indicated by the following:

- change of surface topography

- decreased crypt density

- crypt architectural abnormality (distortion, branching, shortening)

\section{Surface topography}

The normal mucosal surface of the colon and rectum is almost flat (figs $1 \mathrm{a}$ and $1 \mathrm{~b}$ ), although there may be irregularity over lymphoid follicles. In chronic idiopathic IBD, surface irregularity is variable in severity. It may sometimes be sufficiently noticeable to give pseudovillous change. ${ }^{45}$

\section{Crypt density}

The average normal number of crypt profiles corresponding to a $1 \mathrm{~mm}$ length of muscularis mucosae is seven to eight, and the crypts are closely packed. In chronic idiopathic IBD, the crypt density is often reduced to four to five per $\mathrm{mm}$, so that adjacent crypts are separated by lamina propria equivalent to or greater than a crypt diameter. ${ }^{2512}$ Crypt numbers should be assessed along the entire length of wellorientated mucosa with underlying muscularis mucosae but avoiding lymphoid follicles. This is facilitated by knowledge of the field diameters of the microscope. Increased spacing between crypts may be seen in the normal caecal and distal rectal mucosa and should not be confused with inactive chronic idiopathic IBD. ${ }^{13}$

\section{Crypt architectural abnormality}

Normal colorectal crypts are straight, parallel and extend from immediately above the muscularis mucosae to the surface (fig 1a). There is some variation of normal crypt architecture in the region of innominate grooves (fig 1c) and lymphoid follicles. ${ }^{10}$ Crypt distortion implies non-parallel, variable diameter or cystically dilated crypts as opposed to the normal 'test-tube rack' appearance. Crypt branching represents growth or regeneration after injury and is increased in frequency in 

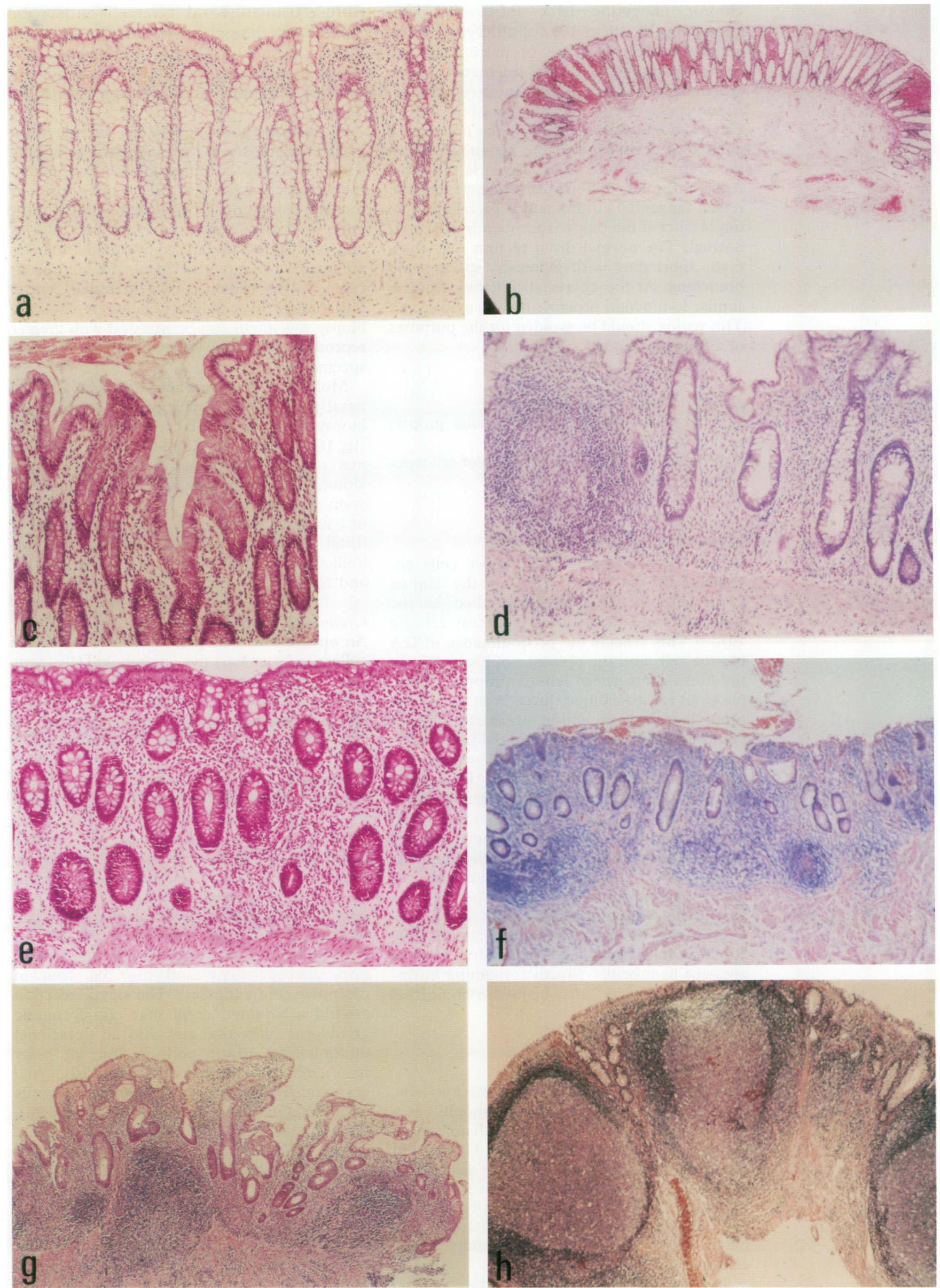

Figure 1 (a) Normal rectal mucosa with an almost flat surface and straight, parallel crypts extending from immediately above the muscularis mucosae to the surface. Most of lamina propria cells are situated in the upper third. (b) An adequate, well orientated rectal biopsy specimen. (c) Normal rectal mucosa in the region of an innominate groove, where several crypts open into one central crypt. (d) Ulcerative colitis showing crypt architectural distortion and surface irregularity with a predominantly diffuse transmucosal increase in lamina propria cells and, at one aspect, a lymphoid follicle. (e) $A$ discontinous increase in lamina propria cells with focal cryptitis and mild architectural distortion in Crohn's disease. (f) Frequent lymphoid aggregates in ulcerative increase in lamina propria cells with focal cryptitis and mild architectural distortion in Crohn's disease. (f) Frequent lymphoid aggregates in ulcerative
colitis. There is also moderate architectural distortion including crypt shortening. $(g)$ Moderate architectural distortion with short surface villous projections and a transmucosal increase in inflammatory cells as well as prominent lymphoid aggregates in ulcerative colitis. (h) Prominent organised lymphoid follicles in ulcerative colitis. 
chronic idiopathic IBD. Infrequent crypt branching (less than $10 \%$ of all crypts) is not abnormal. The presence of more than two branched crypts in a well-orientated biopsy specimen with at least $2 \mathrm{~mm}$ length of muscularis mucosae can be regarded as abnormal. ${ }^{2}{ }^{14}$ Crypt shortening (atrophy) is the presence of an increased, usually variable, distance between the crypt bases and the muscularis mucosae. Apparent, mild, uniform crypt shortening can reflect tangential cutting and is probably of no importance if the biopsy specimen is otherwise normal. The normal distal rectum may show crypt shortening with increased spacing and branching. At the anorectal junction, features similar to mucosal prolapse may also be seen. ${ }^{15}$ This region should be avoided for the purposes of diagnostic biopsy. ${ }^{16}$

\section{LAMINA PROPRIA CELLULARITY}

The assessment of abnormal lamina propria cellularity refers to:

- increase and altered distribution of cell types usually present

- granulomas and giant cells

\section{Normal lamina propria composition}

In the normal large bowel, most cells are situated in the upper third of the lamina propria and the ratio of cellularity between the superficial and basal thirds is almost 2:1 (fig 1a). ${ }^{5}$ This reflects the predominance of IgA plasma cells and the presence of histiocytes in the normal superficial lamina propria. ${ }^{17}$ Lymphocytes are distributed throughout the lamina propria as well as within organised follicles equivalent to Peyer's patches in the small intestine. They may also form less well-defined aggregates. ${ }^{18}$ Lymphoid follicles in normal mucosa often occupy the full mucosal thickness, incorporate crypts at their periphery and may transect the muscularis mucosae, extending into submucosa to form 'lymphoglandular complexes'. ${ }^{19}$ Numbers of eosinophils are highly variable but they are relatively rare compared with plasma cells and lymphocytes. Histiocytes are not easily identified unless they contain conspicuous ingested material such as pigment or mucin. ${ }^{13}$ Mucin containing histiocytes ('muciphages') may be present in normal mucosa. ${ }^{9} 10$

\section{Increased lamina propria cellularity}

An increase in the numbers of plasma cells, lymphocytes, histiocytes, and eosinophils is a feature of all types of colorectal inflammation, and may be the only change seen. Changes in distribution can be assessed more easily than changes in cell numbers. Two major patterns of increased lamina propria cellularity, diffuse and discontinuous, are recognised. These have very different diagnostic implications. $^{45721}$

Two major subgroups are recognised within diffuse increase: a diffuse superficial increase is an increase in lamina propria cell numbers which is confined to the superficial and middle thirds of the lamina propria. A diffuse transmucosal increase is an increase in cellularity throughout the lamina propria but the proportional increase is maximal and best appreciated in the lower third, resulting in a uniform transmucosal distribution of cells (fig 1d). ${ }^{22}$

A discontinuous increase is a variable (focal or patchy) increase in lamina propria cellularity across the biopsy specimen and not confined to the superficial zone (fig le) ${ }^{21} \mathrm{~A}$ discontinuous increase should not be confused with the presence of normal organised lymphoid follicles and aggregates. Organised lymphoid follicles are often well-circumscribed and are recognised by the presence of a germinal centre. Differences of cellularity between multiple biopsy specimens can be assessed with greater reproducibility than variation within a single specimen. ${ }^{21}$

More than two lymphoid aggregates in the basal part of the lamina propria in a $2 \mathrm{~mm}$ biopsy specimen may be considered abnormal (fig 1f). ${ }^{10}$ Unlike lymphoid follicles in the normal mucosa, these lack a germinal centre, although confirmation may require examination of multiple levels. An increased number of lymphoid follicles is a particular feature of distal ulcerative colitis, and an entity of 'follicular proctitis' has been described (figs $1 \mathrm{~g}$ and $1 \mathrm{~h}) .{ }^{2324}$

\section{Granulomas and giant cells}

An epithelioid cell granuloma is a discrete collection of at least five epithelioid cells (activated histiocytes with homogeneous eosinophilic cytoplasm), with or without accompanying multinucleate giant cells (figs $2 a$ and 2b). ${ }^{4}$ This type of well-formed granuloma is a very specific indicator of Crohn's disease, ${ }^{425}$ although they are not a sensitive feature, being seen in as few as $18 \%$ of biopsy specimens from patients with known Crohn's disease. ${ }^{26}$ Submucosal location is probably of even higher diagnostic specificity. ${ }^{27}$ Pericryptal histiocytic aggregates and poorly defined, small groups of histiocytes ("microgranulomas") ${ }^{28} 29$ should provoke a particularly thorough search for epithelioid granulomas and other features of Crohn's disease, but on their own they are of unproven specificity and may be seen in ulcerative colitis (fig 2c) ${ }^{30}$ Histiocytic reaction around a ruptured crypt may closely mimic granuloma formation and also an occasional multinucleate giant cell of "foreign body type" may be formed. Isolated histiocytic/ granulomatous reaction to a disrupted crypt is of uncertain diagnostic importance (fig 2d). Granulomas may also be mimicked by a lymphoid germinal centre or by the effect of sectioning through the basal edge of a crypt epithelial lining. ${ }^{21}$ Other causes of granuloma formation are discussed later.

NEUTROPHIL POLYMORPH INFILTRATION

Of the microscopic features of acute inflammation only neutrophil polymorph infiltration of the following compartments can be assessed reproducibly:

- lamina propria

- crypt epithelium (cryptitis) 

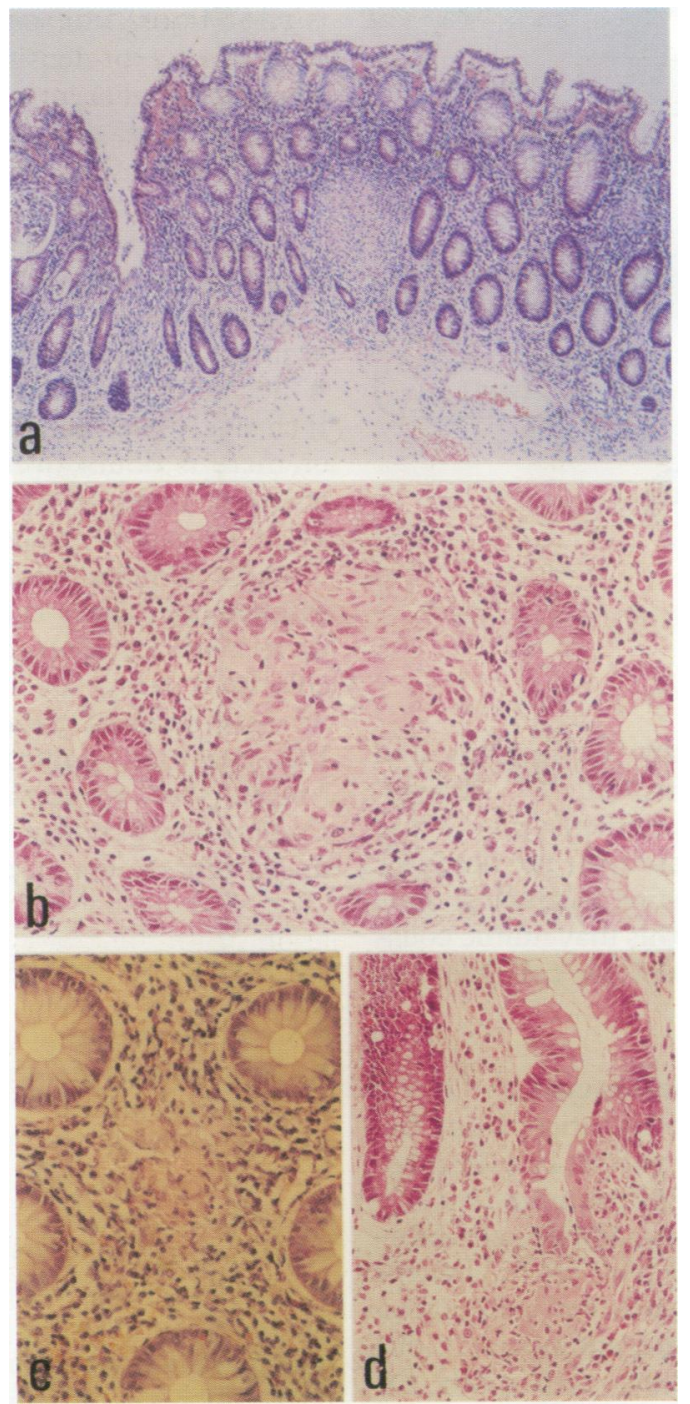

Figure 2 (a) Crohn's disease with mild surface irregularity, mild crypt distortion, focal cryptitis, and granuloma formation. (b) An epithelioid cell granuloma in the lamina propria composed of activated histiocytes with abundant eosinophilic cytoplasm. Small collections of lymphocytes are present at the periphery. (c) $A$ microgranuloma. This is a small aggregate of histiocytes lacking the features of activation seen in (b). (d) $A$ pericryptal histiocytic reaction. This finding is of unproven specificity.

- crypt lumina (crypt abscess)

- surface epithelium

Vigorous bowel preparation may account for occasional neutrophil polymorphs in crypts (less than one to two per crypt) or within surface epithelium of normal bowel. ${ }^{1020213031}$ Neutrophil polymorphs are generally absent from the lamina propria but an occasional polymorph in an otherwise normal biopsy specimen is within normal limits. ${ }^{10}$ In acute infective type colitis, ulcerative colitis and Crohn's disease, there is wide overlap in the numbers and distribution of neutrophil polymorphs depending on the timing of the biopsy in relation to disease onset and activity.

\section{Epithelial abnormality}

POLYMORPH INFLAMMATION MAY BE GRADED ON NUMBERS PER CRYPT OR PER MILLIMETRE IN LAMINA PROPRIA AND BY INVOLVEMENT OF THE THIRDS OF THE BIOPSY SPECIMEN (TABLE 1; FIG 5) The first three of the following features relate to the diagnosis of chronic idiopathic IBD. The others relate to specific, uncommon types of colitis:

- mucin depletion

- surface epithelial damage

- metaplastic changes

- surface intraepithelial lymphocytes

- apoptosis

- subepithelial collagen

\section{Mucin depletion}

This is a reduction in number of goblet cells or depleted mucin within cells. It is non-specific, but severe mucin depletion occurs with greater frequency in ulcerative colitis than Crohn's disease. ${ }^{4233}$

\section{Surface epithelial damage}

Cuboidal change or flattening reflects mild mucosal damage and cell restitution. ${ }^{34}$ More noticeable degenerative change is indicated by cell vacuolation and focal cell loss. Focal damage may accompany vigorous bowel preparation. ${ }^{31}{ }^{35}$ Erosion is loss of surface epithelium with underlying inflammation whereas ulceration is indicated by damage to a greater thickness with underlying granulation tissue. Biopsy trauma may result in artefactual stripping of surface epithelium and "squeezing out" of crypt epithelium, resulting in residual slit-like spaces and an apparent decrease in crypt numbers.

\section{Metaplastic change}

Paneth cell metaplasia and appearance of cells of the ulcer-associated cell lineage (pseudo-pyloric metaplasia) ${ }^{36-38}$ are indicators of chronic epithelial cell damage but their diagnostic value is unclear. Epithelial change resembling that seen in metaplastic polyps may be seen in chronic ulcerative colitis. ${ }^{38}$

\section{Intraepithelial lymphocytes}

The reported counts in normal mucosa, chronic idiopathic IBD and acute colitis are less than five per 100 epithelial cells. In lymphocytic colitis, these are notably increased to greater than 20 per $100 .{ }^{39-41}$ Intraepithelial lymphocytes may also be increased in colorectal biopsy specimens from patients with coeliac disease. ${ }^{41}$ In the normal mucosa, epithelium immediately overlying a lymphoid follicle is flat and heavily infiltrated by lymphocytes. $^{919}$

\section{Apoptosis}

An occasional apoptotic body may be seen in normal epithelium, particularly towards the luminal surface. ${ }^{10}$ Apoptosis is abnormal if present in the crypt epithelium or increased in surface epithelium. This is seen with nonsteroidal anti-inflammatory drugs (NSAIDs), graft versus host disease, HIV infection, and AIDS. ${ }^{42-47}$

\section{Subepithelial collagen}

The subepithelial collagen layer of the normal mucosa is no thicker than $3 \mu \mathrm{m} .{ }^{30}$ In collagenous colitis, it exceeds $10 \mu \mathrm{m}$, although in this 


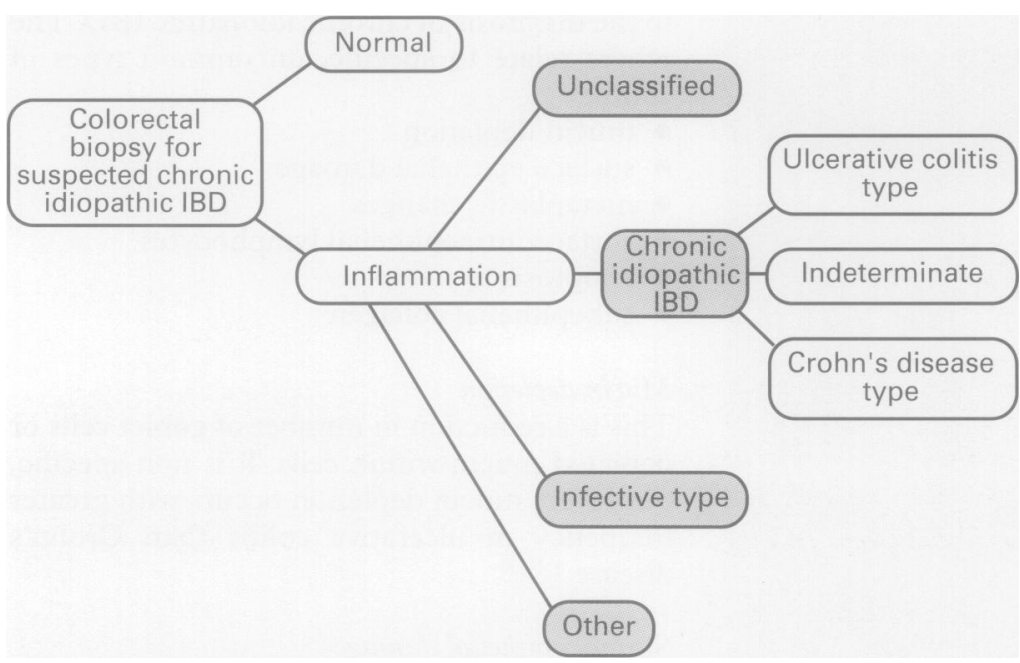

Figure 3 The diagnostic groups on which clinical decisions depend.

disease its presence may be patchy and confined to the proximal colon. ${ }^{23}$ 48-50 Tangential cutting of biopsy specimens may cause apparent thickening of basement membrane ${ }^{10}$; together with the eosinophilic subnuclear zone of surface epithelial cells, this may mimic collagenous colitis. Special stains for collagen may be helpful.

\section{Approach to biopsy assessment}

The clinician requires information from the biopsy report to place the patient in a diagnostic group (fig 3). Although examination of a biopsy specimen without additional information can avoid cognitive bias, the full benefit of the pathologist's experience and opinion can only be obtained if adequate, appropriate clinical information is available, particularly for some rarer inflammatory processes (fig 4). The timing of biopsy in relation to the onset of current clinical activity of disease should be known. Discussing difficult cases directly with the clinician and establishing regular clinicopathological meetings is important.

Initial low power examination will provide information on the mucosal architecture and pattern of lamina propria cellularity. Higher power examination can then assess the lamina propria cell numbers and distribution, neutrophil polymorph infiltration, and epithelial abnormality. Optimum assessment is only possible if the biopsy specimen is of adequate size, contains the full thickness of the mucosa and muscularis mucosae, and the sections are orientated perpendicular to the plane of the mucosa with most crypts cut longitudinally (fig $1 \mathrm{~b}$ ).$^{13}$ Multiple levels should be examined where appropriate. The following five questions allow the pathologist to place the biopsy specimen into a diagnostic group:

- Is the mucosa normal or inflamed?

- Are there features of chronic idiopathic IBD?

- If the features suggest chronic idiopathic IBD, do they favour a diagnosis of ulcerative colitis or Crohn's disease?

- Are there features suggestive of acute infective type colitis?

- Do the features represent another form of inflammation?
IS THE MUCOSA NORMAL OR INFLAMED?

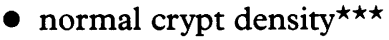

- undistorted crypt architecture $e^{\star \star \star}$

- flat mucosal surface ${ }^{\star \star \star}$

- normal density, distribution and population of lamina propria cells without granulomas and giant cells $\star \star \star$

- no neutrophil polymorph infiltration (see earlier) $)^{\star \star \star}$

- intact, columnar, surface epithelium ${ }^{\star \star \star}$

- normal mucin content of goblet cells $\star \star$

If chronic idiopathic IBD is suspected clinically or there is doubt over mild or discontinuous changes, multiple levels of the biopsy specimens should be examined. In patients with Crohn's disease and very occasionally in inactive ulcerative colitis, particularly where there is no macroscopic evidence of disease, a colorectal biopsy specimen may appear normal or show minimal variation from normality. ${ }^{3251}$ Discontinuous inflammation, intraepithelial lymphocytes, subepithelial collagen, and mucosal prolapse changes should be sought before finally reporting a biopsy specimen as normal.

\section{ARE THERE FEATURES OF CHRONIC IDIOPATHIC} IBD?

- crypt architectural distortion ${ }^{\star \star \star}$

- decreased crypt density ${ }^{\star \star \star}$

- irregular surface ${ }^{\star \star \star}$

- transmucosal or discontinuous increased lamina propria cells $\star \star \star ~$

- epithelioid granulomas $\star \star \star$

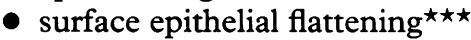

- neutrophil polymorph infiltration ${ }^{\star \star}$

A combination of architectural abnormalities which are usually absent in infection, transmucosal increased lamina propria cellularity which is much less notable in infective type colitis than in chronic idiopathic IBD, and epithelial changes can distinguish between chronic idiopathic IBD and acute infective type colitis or other causes of colorectal inflammation in most cases. ${ }^{23} 30335253 \mathrm{~A}$ discontinuous increase in lamina propria cellularity at the level of a single biopsy specimen may be seen in both Crohn's disease and infective type colitis. In acute onset disease after several weeks large numbers of neutrophils, especially crypt abscesses, with more than 10 neutrophils per crypt, are suggestive of chronic idiopathic IBD. ${ }^{5}$ Causes of granuloma formation other than Crohn's disease include infections such as tuberculosis, atypical mycobacterial infection, chlamydia, yersinia, schistosomiasis, and fungal infection, as well as foreign body reaction, diversion colitis and sarcoidosis. ${ }^{3054-61}$

Granulomas may be seen rarely as an isolated finding in an otherwise normal biopsy specimen and after salmonella and campylobacter colitis. ${ }^{13}$

IF THE FEATURES SUGGEST CHRONIC IDIOPATHIC IBD, DO THEY FAVOUR A DIAGNOSIS OF ULCERATIVE COLITIS OR CROHN'S DISEASE?

Ulcerative colitis type

- severe crypt architectural distortion $\star \star \star$

- severe, widespread, decreased crypt density $\star \star \star$ 
- frankly villous surface ${ }^{\star \star \star}$

- heavy, diffuse transmucosal lamina propria cell increase ${ }^{\star \star \star}$

- severe mucin depletion ${ }^{\star \star}$

Crohn's disease type

- epithelioid granulomas ${ }^{\star \star \star}$

- discontinuous crypt distortion $\star \star \star$

- discontinuous inflammation ${ }^{\star \star}$

- focal cryptitis ${ }^{\star}$
Differential diagnosis depends mainly on the more severe architectural abnormality and greater density and transmucosal distribution of lamina propria cellularity in active ulcerative colitis (figs $1 \mathrm{~d}, 1 \mathrm{f}, 1 \mathrm{~g}$, and $1 \mathrm{~h}$ ). In Crohn's disease, variable milder architectural abnormality and epithelioid granulomas are accurate features (figs 1e, 2a and 2b). Discontinuous inflammation and focal cryptitis in a single
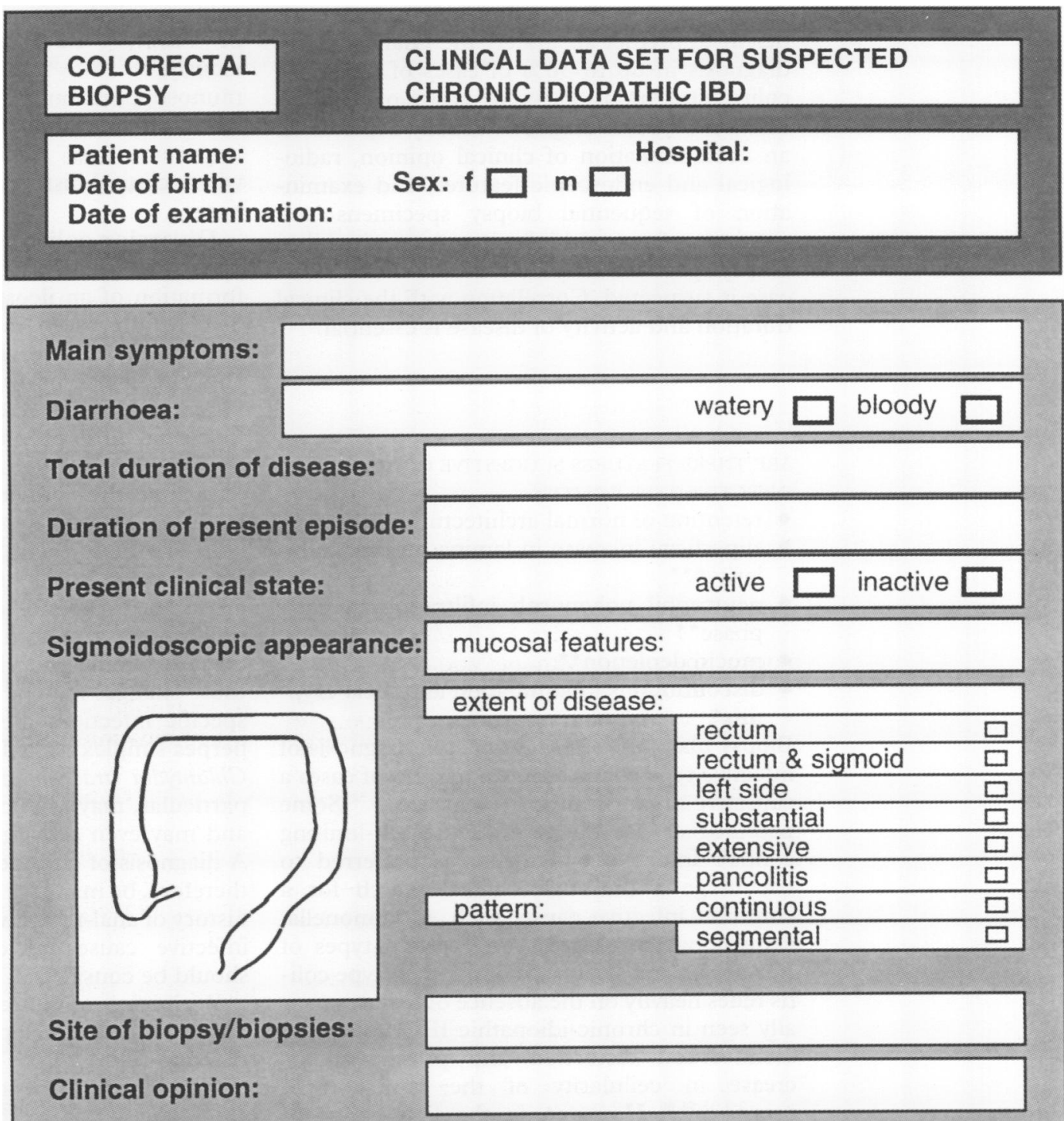

\section{ADDITIONAL INFORMATION (IF APPROPRIATE)}

Include previous gastrointestinal surgery, therapy, results of stool culture, other diseases present.

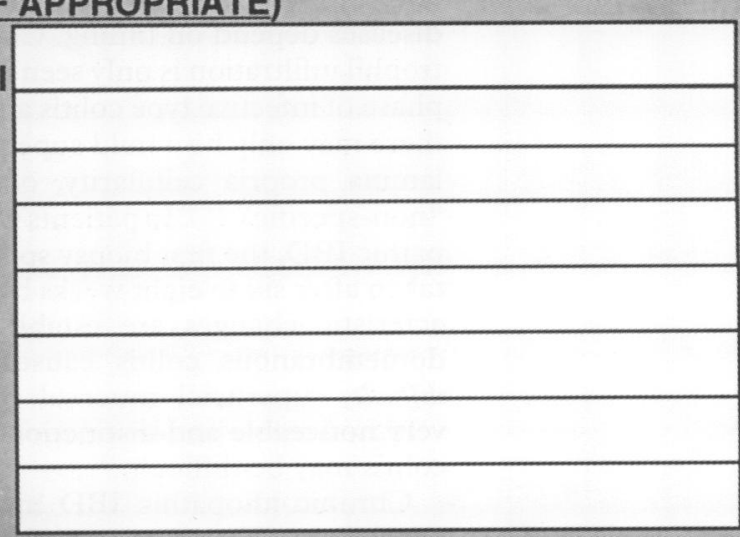

Figure 4 The minimum information required by the pathologist for optimum interpretation of the biopsy specimen. 
biopsy specimen are rated as important by experts but are poorly reproducible and may be seen in resolution of active ulcerative colitis. ${ }^{62}$ Polymorph infiltration is a feature of both, although focal infiltration is a feature of Crohn's disease. In Crohn's disease, and occasionally inactive ulcerative colitis, only very mild abnormalities may be present. ${ }^{32} 51$ Thickening of the muscularis mucosa may be seen in ulcerative colitis. ${ }^{63}$ The histological appearances of the biopsy specimen alone are not sufficient to predict accurately the final definitive diagnosis in up to $30 \%$ of cases of ulcerative colitis and up to $60 \%$ of cases of Crohn's disease. ${ }^{64}{ }^{65}$ Final diagnosis usually depends on an accummulation of clinical opinion, radiological and endoscopic features, and examination of sequential biopsy specimens and specimens from multiple sites. A terminal ileal biopsy specimen may be useful if Crohn's disease is suspected. Correlation with the clinical duration and activity of disease is essential.

ARE THERE FEATURES SUGGESTIVE OF ACUTE INFECTIVE TYPE COLITIS?

- retention of normal architecture ${ }^{\star \star \star}$

- superficial increase in lamina propria cellularity $\star \star \star$

- neutrophil polymorph infiltration in early phase $^{\star \star}$

- mucin depletion ${ }^{\star \star}$

- discontinuous inflammation and focal cryptitis*

Biopsy plays an important part in diagnosis of infective type colitis as in up to $60 \%$ of cases a causative organism is not identified. ${ }^{33}{ }^{52}$ Some pathologists use the term 'acute self-limiting colitis'. Infective type colitis is preferred to encourage a thorough clinical search for a common infective cause, such as salmonella, campylobacter, shigella, and certain types of Escherichia coli. Diagnosis of infective type colitis relies heavily on the absence of features usually seen in chronic idiopathic IBD, especially architectural distortion and prominent increase in cellularity of the lamina propria. $^{2335466}$ However, in the first attack of chronic idiopathic IBD, it may be difficult to distinguish between infective type colitis and chronic idiopathic IBD. Features of both diseases depend on timing. Classic, florid neutrophil infiltration is only seen in the early acute phase of infective type colitis and by two weeks, there may only be a mild superficial increase in lamina propria cellularity, often reported as "non-specific". ${ }^{33}{ }^{54}$ In patients with chronic idiopathic IBD, the first biopsy specimen is usually taken after six to eight weeks by when the characteristic changes are established. ${ }^{3}$ In pseudomembranous colitis caused by Clostidium difficile, superficial mucosal damage may be very noticeable and distinction from ischaemic colitis may be difficult. ${ }^{32}$

Chronic idiopathic IBD may, on occasion, apparently be triggered by an infective episode. ${ }^{67}{ }^{68}$ Chronic shigellosis, in particular, may mimic chronic idiopathic IBD.$^{67}$ If there is any doubt over the diagnosis, patients should be followed. ${ }^{69}$

DO THE FEATURES REPRESENT ANOTHER FORM OF INFLAMMATION?

Inflammation which is inconsistent with chronic idiopathic IBD or typical infective type colitis should lead to detailed clinical and histological assessment to identify rare forms of colitis, including rare infections. These types of colitis have been reviewed previously. ${ }^{93032565970}$ Information regarding immunosuppression, HIV status, diversion of the faecal stream, and drugs is essential. Several important and recently described diseases where clinical history is essential are described here.

Diversion colitis is colorectal inflammation occurring in the defunctioned bowel after formation of an ileostomy or colostomy. ${ }^{56}{ }^{71-73}$ The features seen include inflammatory cell infiltration with varying degrees of epithelial abnormality, crypt distortion, lymphoid hyperplasia, and, in severe cases, ulceration. Granulomas have also been described. ${ }^{58}$ The changes are non-specific but may closely mimic chronic idiopathic IBD and erroneous diagnosis could lead to inappropriate management. ${ }^{74}$

In association with anal-receptive sexual intercourse, local histological abnormalities are frequent and include neutrophil polymorph infiltration, architectural distortion and increased lamina propria cellularity. ${ }^{57}$ Although these changes may be seen in the absence of a specific infection, there is often infection by herpes simplex virus II, Treponema pallidum or Chlamydia trachomatis. The latter two, in particular, may mimic chronic idiopathic IBD and may even show granuloma formation. ${ }^{56} 57$ A diagnosis of chronic idiopathic IBD should, therefore, be made with caution when there is a history of anal-receptive sexual intercourse and infective causes of colorectal inflammation should be considered. ${ }^{55} 57$

Recipients of bone marrow transplants are at risk of developing graft versus host disease (GvHD). ${ }^{30}$ The effects of GvHD on the colorectal mucosa include changes which are difficult to recognise soon after the transplant as similar changes may be produced by the effects of cytotoxic drugs, irradiation or viral infection, particularly cytomegalovirus (CMV). ${ }^{29} 3076$ An absolute diagnosis of GvHD cannot, therefore, be made in the first few days after transplantation or in the presence of CMV inclusions. ${ }^{76} 77$ In acute GvHD, the changes are mainly those of crypt epithelial degeneration and may be focal. ${ }^{44}$ There is epithelial cell degeneration with prominent apoptosis in crypt bases, ${ }^{29}$ crypt dilation and crypt abscesses. There may be selective sparing of endocrine cells at crypt bases and groups of such cells in the lamina propria represent the residuum of damaged crypts. ${ }^{78}$ Late, severe, acute disease may be associated with complete mucosal loss and haemorrhage. ${ }^{79}$ Mucosal biopsy is usually unhelpful in the chronic phase as the changes are mainly submucosal and serosal. ${ }^{76}$ 
In association with HIV infection, nonspecific colorectal changes have been described in the absence of detection of any other, local, infectious agent. ${ }^{45}$ The changes in the lamina propria may include an increase in cellularity, oedema or, rarely, a decrease in cellularity. ${ }^{77} 80$ Occasional damaged crypts and small crypt abscesses may be seen. AIDS or other forms of immunosuppression should provoke particularly careful search for features of infection by Mycobacterium avium-intracellulare, CMV, herpes simplex virus, cryptosporidia, and amoebae, amongst others. ${ }^{5598}$ A search for amoebae should be made wherever surface purulent material is seen. ${ }^{32} 8283$ Apoptosis has been described in AIDS, particularly involving bases of crypts. ${ }^{46} 47$

Microscopic colitis is a clinicopathological syndrome defined by the presence of histological inflammation in the absence of definite endoscopic or radiological abnormality; it often presents as chronic watery diarrhoea. ${ }^{23} 394084$ This category includes the relatively welldefined groups of lymphocytic and collagenous colitis but chronic idiopathic IBD (minimal change colitis), ${ }^{85}$ autoimmune disease, $\mathrm{GvHD},{ }^{44}$ and drug-induced inflammation can present as this syndrome. Microscopic colitis should be regarded as an umbrella term for any colitis in which there is histological, but no colonoscopic, abnormality and, to avoid confusion, should be qualified-for example, microscopic colitis of collagenous, lymphocytic or other specified type. $^{86} 87$

Many drugs including NSAIDs, gold, penicillamine, and antibiotics can lead to inflammatory changes of the large bowel mucosa. 4243597088

\section{Reaching an opinion on diagnosis and writing a report}

A reporting proforma or checklist is shown which can be useful for collecting, grading and recording relevant information (fig 5). This could be used as an alternative to the usual descriptive type of histopathology report. The model suggested is relevant to single biopsy specimens but modification may be desirable for recording information from multiple colonoscopic specimens. After full assessment of the biopsy specimen, the pathologist should be able to place the specimen in a histopathological category (table 2), although final diagnosis requires both clinical and pathological information. If a descriptive report is given, this should be concluded with the relevant category.

Confirming microscopic as well as macroscopic normality of the colorectal mucosa at the initial investigation of active disease directs further investigation away from ulcerative colitis and infective type colitis towards functional diarrhoea and irritable bowel syndrome, although Crohn's disease cannot be excluded. The term inflammation-unclassified is used to indicate cases which show inflammation requiring further investigation but the features are insufficient to indicate a specific disease category. Chronic idiopathic IBD is divided into ulcerative colitis type and
Table 2 Reporting system for colorectal biopsy specimens

Normal

Inflammation-unclassified

Chronic idiopathic IBD

- indeterminate

- ulcerative colitis typef

- Crohn's disease typet

Infective type colitis

Other colitis (specified)

tWith probability assessment: (highly) suggestive.

Crohn's disease type. It is suggested that the category indeterminate is extended to those cases in which it is not possible to make a distinction. This term is already applied to resection specimens in which a definite diagnosis cannot be made, usually because of fulminant acute disease with severe inflammation and extensive deep ulceration. ${ }^{89}$

There is often diagnostic uncertainty about either the presence of chronic idiopathic IBD, or the distinction between ulcerative colitis and Crohn's disease. For effective communication, statement of the subjective grade of probability attached to the diagnosis should be standardised to avoid ambiguity from the use of multiple terms. Suggestive is recommended when the pathologist favours one diagnosis but is not certain without clinical or other information. The pathologist may wish to give a differential diagnosis. Highly suggestive should be used when typical features are present permitting a definite histological opinion but full clinical follow up and correlation are not possible. The pathologist should point out the importance of supplying appropriate clinical information to his or her colleagues in these circumstances. A final diagnosis can only be made with the full clinical information and a biopsy specimen should be reported as diagnostic only if full supportive clinical information is available.

Histological activity of chronic idiopathic IBD may be graded by severity of neutrophil polymorph infiltration, of lamina propria cellularity, of epithelial damage, and of architectural abnormality. Single biopsy specimen changes relate more closely to clinical activity in ulcerative colitis than in Crohn's disease but current grading schemes are not regarded as clinically useful in routine practice, except for distal proctosigmoiditis.

\section{Conclusion}

These guidelines have been produced to encourage pathologists to use validated, accurate and reproducible criteria for diagnosing inflammation on the initial colorectal biopsy specimen for suspected chronic idiopathic IBD. Protocols have been developed for recording relevant microscopic features and clinical information. The guidelines recommend reporting conclusions in standard, clinically relevant categories which state the level of subjective, diagnostic uncertainty. This addresses general criticism of the variable use and ambiguous interpretation of terms expressing uncertainty in histopathology reports. ${ }^{90}$

The literature review and critical appraisal have shown that many histological features used conventionally in interpreting colorectal 
inflammation are neither reproducible nor discriminatory for important clinical decisions. The major phenotypes of the common types of chronic idiopathic IBD, Crohn's disease and ulcerative colitis in mucosal biopsy specimens are defined by the extent and distribution of mucosal architectural abnormality and of lamina propria cellularity. Polymorph infiltration is common to both and very variable. Mucin depletion is specific for ulcerative colitis only if severe. Well-formed epithelioid granulomas are specific but insensitive for Crohn's dis-

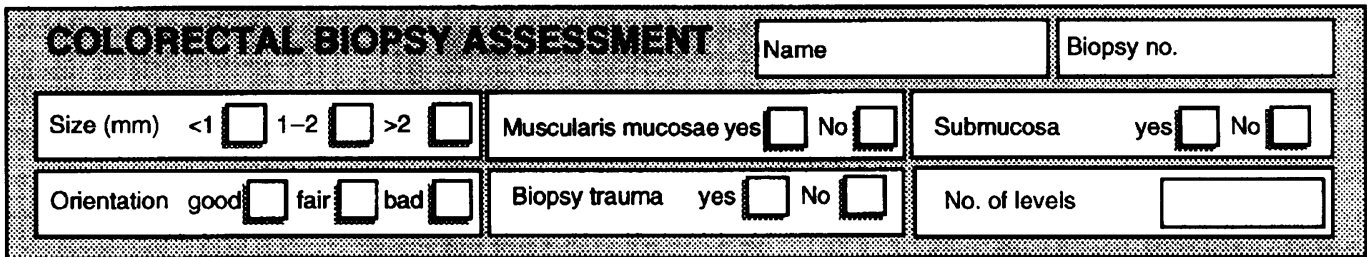

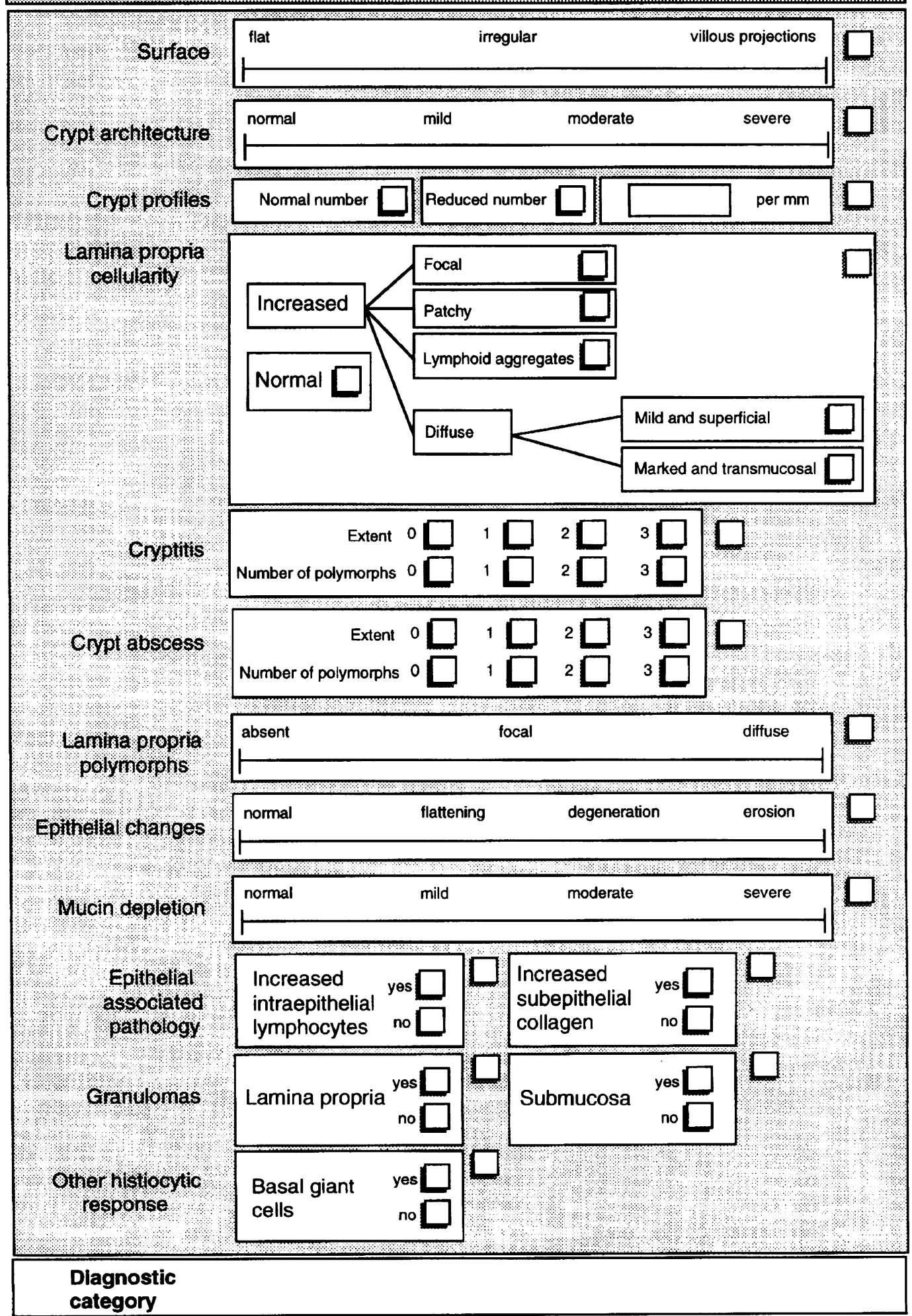

Figure 5 Reporting proforma for colorectal biopsy specimens. 
ease. Discontinuous inflammation and focal cryptitis are regarded by experts as important discriminating features of Crohn's disease but have not been validated by precise diagnostic research. These conclusions and the evidencebased standards derived permit more accurate definition and consistent classification of disease phenotype and histological activity for genetic and molecular studies. ${ }^{91}$

Very few of the primary pathology publications reviewed met the stringent standards of clinical epidemiological design for studies of diagnosis recommended by the EvidenceBased Medicine Working Party and used in meta-analysis. ${ }^{8}$ The poor evaluation of histopathological diagnosis was no different to that reported for diagnostic tests in general. ${ }^{92}$ Few of the pathological publications reviewed reported reproducibility or accuracy; most studies are case series which are often small and represent individual, specialist and selective practice. Much diagnostic information was presented in review or textbook format by authorities without supporting data or formal analysis. Serious limitations apply particularly to evidence on the optimal use of multiple colonoscopic and sequential biopsy specimens and to some less common colitides.

The systematic review was supplemented through detailed discussion by an expert consensus panel at several meetings to identify further evidence, develop criteria and recommend their application. The draft guidelines were then submitted to a second round of external review by independent experts whose comments were incorporated when supported by evidence. Formal evaluation of the guidelines and protocols in practice is being undertaken and it is planned that this will lead to further revision and development. The multi-stage cycle of development corresponds closely to that adopted by Browman et al..$^{93}$ The "checklist" protocol for microscopy is in line with proposals for general use of such aids to accurate and complete reporting. ${ }^{94} 95$ The checklist also provides the basis for a formal decision support system, for access through information technology to additional diagnostic information and for generating template reports. It incorporates grading of individual changes by analogue and categorical scales. This provides a flexible mechanism for recording histological activity of inflammation and severity of other changes in multiple dimensions which can be used to develop indices for specific clinical purposes.

The guidelines were prepared on behalf of the British Society of Gastroenterology for routine practice and their use as a European standard is under discussion. ${ }^{96}$ The guidelines form the first stage in developing a systematic, evidence-based approach to the use and interpretation of biopsy specimens in chronic idiopathic IBD and indicate a need for high quality clinical research to apply a stringent approach where practice is based largely on "oral tradition". ${ }^{97}$. The evidence-based approach offers much to develop the clinical effectiveness of histopathology in diagnosis and prognosis in gastroenterology and elsewhere through focus on the clinical setting, problems and outcomes, and on accuracy and reproducibility. Guidelines, checklists and template reports are an appropriate way of applying this approach and improving communication through standardisation of the textual report. With information technology to ease implementation, these approaches can support, improve and standardise expert but subjective, pathological diagnosis.

We wish to thank Professor CJ Hawkey and Dr B Scott for comment on clinical managment of chronic idiopathic IBD, and also Professor GNJ Tytgat, Dr K Geboes, Dr WV Bogomoletz, Dr N Professor GNJ Tytgat, Dr K Geboes, Dr WV Bogomoletz, Dr N
Ectors, Dr J Offerhaus, Professor M Stolte, and Dr R Edwards Ectors, Dr J Offerhaus, Professor M Stolte, and Dr R Edwards
for advice and comment, Mr D Hughes and Miss A Kane for for advice and comment, Mr D Hughes and Miss A Kane for
photographic assistance, and Professor J Lowe for help in designing the biopsy reporting proforma.

1 Cook MG, Dixon MF. An analysis of the reliability of detection and diagnostic value of various pathological features in
Crohn's disease and ulcerative colitis. Gut 1973;14:255-62.

2 Surawicz CM, Belic L. Rectal biopsy helps to distinguish acute self-limited colitis from idiopathic inflammatory bowel disease. Gastroenterology 1984;85:104-13.

3 Allison MC, Hamilton-Dutoit SJ, Dhillon AP, Pounder RE. The value of rectal biopsy in distinguishing self-limited colitis from early inflammatory bowel disease. $Q \mathcal{F}$ Med 1987;65:985-95.

4 Seldenrijk CA, Morson BC, Meuwissen SGM, Schipper $\mathrm{NW}$, Lindeman J, Meijer CJL. Histopathological evaluation of colonic mucosal biopsy specimens in chronic inflammatory bowel disease: diagnostic implications. Gut 1991;32: 1514-20.

5 Jenkins D, Goodall A, Drew K, Scott BB. What is colitis? Jenkins $\mathrm{D}$, Goodall A, Drew K, Scott BB. What is colitis?
Statistical approach to distinguishing clinically important inflammatory change in rectal biopsy specimens. F Clin Pathol 1988;41:72-9.

6 Lessells AM, Swanson Beck J, Burnett RA, Howatson SR, Lee FD, McLaren KM, et al. Observer variablility in the histopathological reporting of abnormal rectal biopsy specimens. F Clin Pathol 1994;47:48-52.

7 Theodossi A, Spiegelhalter DJ, Jass J, Firth J, Dixon MF, Leader $M$, et al. Observer variation and discriminatory value of biopsy features in inflammatory bowel disease. Gut 1994;35:961-8.

8 Jaeschke R, Guyatt G, Sackett DL. Users guide to the medical literature. III. How to use an article about a diagnostic test. B. What are the results and will they help me in caring for my patients. F $A M A$ 1994;271:703-7.

9 Goldman H, Antonioli DA. Mucosal biopsy of the rectum colon and distal ileum. Hum Pathol 1982;13:981-1013.

10 Levine DS, Haggitt RC. Normal histology of the colon. Am f Surg Pathol 1989;13:966-84.

11 Morson BC, Dawson IMP, Day DW, Jass JR, Price AB, Williams GT. Normal large intestine. In: Morson and Dawson's liams GT. Normal large intestine. In: Morson and Dawson's Gastrointestinal pathology. 3rd edn.
Scientific Publications, 1990:433-43.

12 Jenkins D, Goodall A, Scott BB. Ulcerative colitis: one disease or two? (Quantitative histological differences between distal and extensive disease). Gut 1990;31:426-30.

13 Talbot IC, Price AB. Assessment of abnormalities: Diagnostic signposts. In: Biopsy pathology in colorectal disease. London: Chapman and Hall, 1987:19-88.

14 Goodman MJ, Kirsner JB, Riddell RH. Usefulness of rectal biopsy in inflammatory bowel disease. Gastroenterology 1977;72:952-6.

15 Talbot IC, Price AB. Ulcerative colitis. In: Biopsy pathology in colorectal disease. London: Chapman and Hall, 1987: in colorecte $261-2$.

16 Goldman $\mathrm{H}$. Interpretation of large intestinal mucosal biopsy specimens. Hum Pathol 1994;25:1150-9.

17 Scott BB, Goodall A, Stephenson P, Jenkins D. Rectal mucosal plasma cells in inflammatory bowel disease. Gut 1983;24:519-24.

18 Thomas HC, Jewell DP. Immunological defence of the gastrointestinal tract: In: Clinical gastrointestinal immunology. London: Blackwell Scientific Publications, 1979:20-3.

19 O'Leary AD, Sweeney EC. Lymphoglandular complexes of the colon: structure and distribution. Histopathology 1986;10:267-83

20 Kealy WF. Colonic lymphoid-glandular complex (microbursa): Nature and morphology. $\mathcal{F}$ Clin Pathol 1976; 29:241-4.

21 Yardley JH, Donowitz $M$. Colorectal biopsy in inflammatory bowel disease. In: Yardley JH, Morson BC, Abell MR, eds. The gastrointesinal tract. Baltimore: Williams and Wilkins, 1977:50-94.

22 Surawicz CM, Haggitt RC, Hussemann M, McFarland LV. Mucosal biopsy diagnosis of colitis: Acute self limited colitis and idiopathic inflammatory bowel disease. Gastroenterology 1994;107:755-63.

23 Bogomoletz WV, Flejou JF. Newly recognised forms of colitis: Collagenous colitis, microscopic (lymphocytic) colitis and lymphoid follicular proctitis. Semin Diagn Pathol 1991;8: 178-89. 
24 Flejou JF, Potet F, Bogomoletz WV, Rigaud C, Fanzy A Lymphoid follicular proctitis. A condition different from ulcerative proctitis? Dig Dis Sci 1988;33:314-20.

25 Giard RWM, Hermans J, Ruiter DJ, Hoedemaeker PJ. Variations in histopathological evaluation of non-neoplastic colonic mucosal abnormalities; assessment and clinical sig nificance. Histopathology 1985;9:535-41.

26 Korelitz BI, Sommers SC. Rectal biopsy in patients with Crohn's disease. Normal mucosa on sigmoidoscopic examination. $f A M A$ 1977;237:2747-54.

27 Talbot IC, Price AB. Crohn's disease. In: Biopsy pathology in colorectal disease. London: Chapman and Hall, 1987:13547.

28 Rotterdam H, Korelitz BI, Sommers SC. Microgranulomas in grossly normal rectal mucosa in Crohn's disease. Am $\mathcal{F}$ Clin Pathol 1977;67:550-4.

29 Whitehead R. Colonic biopsy. In: Mucosal biopsy of the gastrointestinal tract. 4 th edn. Philadelphia: WB Saunders, 1990:285-412.

30 Haggitt RC. The differential diagnosis of inflammatory bowel disease. In: Thomas Norris $\mathrm{H}$, ed. Pathology of the colon, small intestine and anus. 2nd edn. New York: Churchcolon, small intestine and anus.
ill Livingstone, 1991:23-60.

31 Talbot IC, Price AB. The differential diagnosis of inflammatory bowel disease. In: Biopsy pathology in colorectal disease. London: Chapman and Hall, 1987:201-17.

32 Mitros FA. The biopsy in evaluating patients with inflammatory bowel disease. Med Clin North Am 1980;64 1037-57.

33 Nostrant TT, Kumar NB, Appelman HD. Histopathology differentiates acute self-limited colitis from ulcerative colitis. Gastroenterology 1987;92:318-28.

34 Dignass AU, Tsunekawa S, Podolsky DK. Fibroblast growth factors modulate intestinal epithelial cell growth and migration. Gastroenterology 1994;106:1254-62.

35 Saunders DR, Sillery J, Rachmilewitz D, Rubin CE, Tytga $\mathrm{GN}$. Effect of Bisacodyl on the structure and function of rodent and human intestine. Gastroenterology 1977;72:849 56

36 Watson AJ, Roy AD. Paneth cells in the large intestine in ulcerative colitis. F Pathol Bacteriol 1960;80:309-16.

37 Hanby AM, Wright NA. The ulcer-associated cell lineage: The gastrointestinal repair kit? F Pathol 1993;171:3-4.

38 Franzin G, Grigoni WF, Dina R, Scarpa A, Zamboni G. Mucin secretion and morphological changes of the mucosa in non-neoplastic diseases of the colon. Histopathology 1983;7:707-18.

39 Lazenby AJ, Yardley JH, Giardiello FM, Jessurn J, Bayless TM. Lymphocytic ("microscopic") colitis: a comparative histopathological study with particular reference to collagenous colitis. Hum Pathol 1989;20:18-28.

40 Yardley JH, Lazenby AJ, Giardiello FM, Bayless TM. Collagenous, "microscopic", lymphocytic and other gentler and
more subtle forms of colitis. Hum Pathol 1990;21:1089-91.

41 Wolber R, Owen D, Freeman H. Colonic lymphocytosis in patients with celiac sprue. Hum Pathol 1990;21:1092-6.

42 Lee FD. Importance of apoptosis in the histopathology of drug related lesions in the large intestine. $\mathcal{f}$ Clin Patho 1993;46:

43 Lee FD. Drug-related pathological lesions of the intestinal tract. Histopathology 1994;25:303-8.

44 Epstein RJ, McDonald GB, Sale GE, Shulman HM, Thomas ED. The diagnostic accuracy of the rectal biopsy in acute graft versus host disease: A prospective study of thirteen patients. Gastroenterology 1980;78:764-71.

45 Francis N. Light and electron microscopic appearances of pathological changes in HIV gut infection. Baillieres Clin Gastroenterol 1990;4:495-527.

46 Kotler DP, Gaetz HP, Lange M, Klein EB, Holt PR. Enteropathy associated with the acquired immunodeficiency syndrome. Ann Intern Med 1984;101:421-8.

47 Kotler DP, Weaver SC, Terzakis JA. Ultrastructural feature of epithelial cell degeneration in rectal crypts of patients with AIDS. Am f Surg Pathol 1986;10:531-8.

48 Veress B, Lofberg R, Bergman L. Microscopic colitis syndrome. Gut 1995;36:880-6.

49 Lazenby AJ, Yardley JH, Giardiello FM, Bayless TM Pitfalls in the diagnosis of collagenous colitis: Experience
with 75 cases from a registry of collagenous colitis at the with 75 cases from a registry of collagenous colitis at

50 Tanaka M, Mazzoleni G, Riddell RH. Distribution of collagenous colitis: utility of flexible sigmoidoscopy. Gu 1992;33:65-70.

51 Odze R, Antonioli D, Peppercorn M, Goldman H. Effect of topical 5-aminosalicylic acid (5-ASA) therapy on rectal mucosal biopsy morphology in chronic ulcerative colitis. Am F Surg Pathol 1993;17:869-75.

52 Surawicz CM. Diagnosing colitis. Biopsy is best. Gastroenterology 1987;92:538-9.

53 Schumacher G. First attack of inflammatory bowel disease and infective colitis. A clinical, histological and microbiological study with special reference to early diagnosis. Scand 7 Gastroenterol 1993;28:1-24.

54 Whitehead R. Other forms of colitis. In: Mucosal biopsy of the gastrointestinal tract 4th edn. Philadelphia: WB Saunders,

55 Weller IVD. The gay bowel. Gut 1985;26:869-75.

56 Marshall JB, Butt JH. Proctitis: Approach to diagnosis causes and treatment. $\mathcal{F}$ Clin Gastroenterol 1982;4:431-44

57 Surawicz CM, Goodell SE, Quinn TC, Roberts PL, Corey $\mathrm{L}$, Holmes KK, et al. Spectrum of rectal biopsy abnormalienterology 1986;91:651-9.
$58 \mathrm{Ma} \mathrm{CK}$, Gottlieb C, Haas PA. Diversion colitis: A clinicopathologic study of 21 cases. Hum Pathol 1990;21: 429-36.

59 Shepherd NA. Pathological mimics of chronic inflammatory bowel disease. $\mathcal{F}$ Clin Pathol 1991;44:726-33.

60 Sprague R, Harper P, McClain S, Trainer T, Beeken W. Disseminated gastrointestinal sarcoidosis. Case report and review of the literature. Gastroenterology 1984;87:421-5.

61 Bulger K, O'Riordan M, Purdy S, O'Brien M, Lennon J. Gastrointestinal sarcoidosis resembling Crohn's disease. Am $\mathcal{F}$ Gastroenterol 1988;83:1415-17.

62 Tanaka M, Riddell RH. The pathological diagnosis and differential diagnosis of Crohn's disease. Hepatogastroenterology 1990;37:18-31.

63 Talbot IC, Price AB. Ulcerative colitis. In: Biopsy patholog in colorectal disease. London: Chapman and Hall, 1987:122.

64 Morson BC. Histopathology. In: Engel A, Larsen T, eds Regional enteritis (Fifth Skandia International Symposium). Stockholm: Nordiska Bokhandelus Forlag, 1971:15-33.

65 Frei JV, Morson BC. Medical audit of rectal biopsy diagnosis of inflammatory bowel disease. $\mathcal{F}$ Clin Pathol 1982;35: $341-4$

66 Kumar NB, Nostrant TT, Appelman HD. The histopathological spectrum of acute self-limited colitis (acute infectious-type colitis). Am f Surg Pathol 1982;6:523-9.

67 Dronfield MW, Fletcher J, Langman MJS. Coinciden salmonella infections and ulcerative colitis: Problems of recognition and management. BMF 1974;1:99-100.

68 Taylor-Robinson S, Miles R, Whitehead A, Dickinson RJ Salmonella infection and ulcerative colitis. Lancet 1989;i: 1145.

69 Anonymous. Which type of colitis? Lancet 1988;i:336.

70 Tedesco FJ. Differential diagnosis of ulcerative colitis and Crohn's ileocolitis and other specific inflammatory disease of the bowel. Med Clin North Am 1980;64:1173-83.

71 Glotzer DJ, Glick ME, Goldman H. Proctitis and colitis following diversion of the fecal stream. Gastroenterology 1981 80:438-41

72 Komorowski RA. Histologic spectrum of diversion colitis Am F Surg Pathol 1990;14:548-54.

73 Geraghty JM, Talbot IC. Diversion colitis: Histological features in the colon and rectum after defunctioning colostomy. Gut 1991;32:1020-3.

74 Warren BF, Shepherd NA. Diversion proctocolitis. Histopathology 1992;21:91-3.

75 Whitehead R. Human immunodeficiency virus infection and mucosal biopsy. In: Mucosal biopsy of the gastrointestinal tract. 4th edn. Philadelphia: WB Saunders, 1990:433-8.

76 Snover DC. Graft versus host disease of the gastrointestinal tract. Am f Surg Pathol 1990;14(Suppl 1):101-8.

77 Rotterdam H, Tsang P. Gastrointestinal disease in the immunocompromised host. Hum Pathol 1994;25:1123-40.

78 Lampert IA, Thorpe P, Van Noorden S, Marsh J, Goldman JM, Gordon Smith EC, et al. Selective sparing of enterochromaffin cells in graft versus host disease affecting enterochromaffin cells in graft versus host disease affec
the colonic mucosa. Histopathology 1985;9:875-86.

79 Norton J. The histology of graft versus host disease. In: Treleaven J, Barret J, eds. Bone marrow transplantation in practice. Edinburgh: Churchill Livingstone, 1992:275-6.

80 Clayton F, Reka S, Cronin W, Torlakovic E, Sigal SH, Kotler DP. Rectal mucosal pathology varies with human immunodeficiency virus antigen content and disease stage. Gastroenterology 1992;103:919-33.

81 Gazzard B, Blanshard C. Diarrhoea in AIDS and other immunodeficiency states. Baillieres Clin Gastroenterol 1993; 7:387-419.

82 Prathap K, Gilman R. The histopathology of acute intestinal amebiasis. A rectal biopsy study. Am $\mathcal{F}$ Pathol 1970;60:229 46.

83 Pittman FE, Hennigar GR. Sigmoidoscopic and colonic mucosal biopsy findings in amebic colitis. Arch Pathol 1974;97:155-8.

84 Kingham JCC, Levison DA, Ball JA, Dawson AM Microscopic colitis-a cause of chronic watery diarrhoea. BMF 1982;285:1601-4

85 Elliott PR, Williams CB, Lennard-Jones JE, Dawson AM, Bartram CI, Thomas BM, et al. Colonoscopic diagnosis of minimal change colitis in patients with a normal sigmoidosminimal change colitis in patients with a normal sigmoidoscopy and

86 Levison DA, Lazenby AJ, Yardley JH. Microscopic colitis cases revisited. Gastroenterology 1993;105:1594-6.

87 Bogomoletz WV, Flejou J-F. Microscopic colitis: A "transatlantic" unifying concept. Gastroenterology 1994;107:1727.

88 Warren BF, Shepherd NA. Iatrogenic pathology of the gastrointestinal tract. In: Kirkham N, Hall P, eds. Progress in pathology. Vol 1. Edinburgh: Churchill Livingstone, 1995

89 Price AB. Overlap in the spectrum of non-specific inflammatory bowel disease-"colitis indeterminate". $\mathscr{f}$ Clin Pathol 1978;31:567-77.

90 Attanoos RL, Bull AD, Douglas-Jones AG, Fligelstone LJ Semararo D. Phraseology in pathology reports. A comparative study of interpretation among pathologists and surgeons. F Clin Pathol 1996;49:79-81.

91 Jenkins D. Colorectal biopsy reporting - A clinician friendly approach. In: Tytgat GNJ, Bartelsman JFWM, van
Deventer SJH, eds. Falk symposium 85-Inflammatory bowel diseases. Dordecht: Kluwer Academic Publishers, 1995 153-61.

92 Reid MD, Lachs MS, Feinstein AR. Use of methodological standards in diagnostic test research. $\mathscr{F} A M A$ 1995;274 $645-52$. 
93 Browman GP, Levine MN, Mohide EA, Hayward RSA, Pritchard KI, Gafni A, Laupacis A.The practice guidelines development cycle: A conceptual tool for practice
guidelines development and implementation. $₹$ Clin Oncol guidelines develo

94 Markel SF, Hirsch SD. Synoptic surgical pathology reporting. Hum Pathol 1991;22:807.

95 Rosai J. Standardised reporting of surgical pathology diagnosis for the major tumour types. Am $\mathcal{f}$ Clin Pathol 1993;100:240-55.
96 Offerhaus GJA. Compte rendu de biopsie colorectale dans des maladies inflammatoires chroniques de l'intestine (MICI) - etape ulterieure d'une unification europeenne. Acta Endoscopica 1996;26:97-106.

97 Riddell RH. Algorithms for the histological diagnosis of IBD: fact, hope and fantasy. In: Tytgat GNJ, Bartelsman JFWM, van Deventer SJH, Inflammatory bowel diseases. Dordecht: Kluwer Academic Publishers, 1995:122-32.

\section{Molecular Pathology-February 1997 contents}

\section{Reviews}

Human papillomavirus, integration and cervical carcinogenesis: a clinicopathological perspective

K Cooper, $\mathcal{F}$ O’D $M c G e e$

Kaposi sarcoma associated herpes virus (KSHV/HHV 8): epidemiology, molecular biology and tissue distribution

F F O'Leary, $M$ M Kennedy, F O'D McGee

\section{Papers}

Intracellular staining of $\mathrm{Mx}$ proteins in cells from peripheral blood, bone marrow and skin A N Al-Masri, $T$ Werfel, $D$ fakschies, $P$ von Wussow

Oligoclonal populations of $\mathrm{T}$ and $\mathrm{B}$ cells in a case of angioimmunoblastic T-cell lymphoma predominantly infiltrated by $\mathrm{T}$ cells of the VB5.1 family

E Hodges, C T Quin, D H Wright, $\mathcal{f} L$ Smith

p53 gene mutations in multiple myeloma

$R G$ Owen, $S A A$ Davis, $\mathcal{F}$ Randerson, $A C$ Rawstron, $F$ Davies, $\mathcal{f} A$ Child, et al

Immunocytochemical expression of growth factors by odontogenic jaw cysts

T Li, R M Browne, $\mathcal{F} B$ Matthews

Expression of bcl-2 in bladder neoplasms is a cell lineage associated and p53-independent event

Q-L Lu, M Laniado, P D Abel, GW H Stamp, E-N Lalani

The product of the imprinted $\mathrm{H} 19$ gene is an oncofetal RNA

I Ariel, S Ayesh, E f Perlman, G Pizov, V Tanos, $T$ Schneider, et al

Determination of penicillin susceptibility of Streptococcus pneumoniae using the polymerase chain reaction

H Falal, $S$ Organji, $\mathcal{F}$ Reynolds, D Bennett, E O'Mason fnr, $M$ R Millar

\section{Short reports}

Male pseudohermaphroditism resulting from a novel mutation in the human steroid $5 \alpha$-reductase type 2 gene (SRD5A2)

$R$ Anwar, $S$ G Gilbey, $\mathcal{F} P$ New, A F Markham

Additional TCR V $\beta$ primers and minor method modifications improve detection of clonal T-cell populations by RT- PCR

C Lynas, $D$ Howe

\section{Miscellanea}

Instructions for Authors 